\title{
Transient Behavior of CFRP Tensegrity System in a Suspen-dome
}

\author{
IfeOlorun Olofin ${ }^{a^{*}}$, Ronggui Liu ${ }^{\text {a }}$ \\ ${ }^{a}$ Departmentof Civil Engineering and Solid Mechanics, Jiangsu University, No301Xuefu Road, Zhenjiang,212013, China.
}

Received 25 July 2017; Accepted 28 August 2017

\begin{abstract}
In order to establish a conclusive result for the application of carbon fibre reinforced polymer (CFRP) cable as a tensegrity system for a suspen dome, the structural integrity assessment of the system, subjected to transient load, must be considered. This paper gives a preliminary assessment of the dynamic behavior of carbon fibre reinforced polymer cable in a suspen dome in comparison with that of the steel counterpart, using a small model of $4 \mathrm{~m}$ span and $0.4 \mathrm{~m}$ rise. A commercial finite element software namely ANSYS was used for the structure simulation in respect of the experimental design. The results from the simulation show that the carbon fibre reinforced polymer cable gives a reliable assessment as the steel counterpart. The natural frequencies of CFRP cables are higher than those of steel cables due to the CFRP cables' high stiffness-toweight ratio and less curvature under gravity loads. CFRP cables influence the structure with good stiffness which provides good vibration resistance. The results also indicate that from a technical point of view, carbon fibre reinforced polymer cables can perform better than steel cables as tensegrity system for a suspen dome. It is concluded that CFRP cables can be applied to replace steel ones as tensegrity system for a suspen dome.
\end{abstract}

Keywords: Suspen dome; CFRP Tensegrity System; Steel Tensegrity System; Modal Analysis; Transient Analysis.

\section{Introduction}

A suspen dome is a fascinating structure, based on its architectural design and construction point of view [1].this new structure was created by Kawaguchi and his team. It is made up of a single-reticulated layer and a tensegrity system (Strut, hoop and radical cables) [2] as illustrated in Figure 1. The tensegrity system in this structure plays a salient role.With its high strength-to-weight ratio, a tensegrity system gives an outstanding appearance that provides opportunities for engineers to explore new innovation and ideas to produce an excellent structural form. Long span structures are becoming more popular because of their many advantages which include efficient load resistance, light weight and smaller cross-sections. These advantages can be improved on with better cable stiffness and strength-toweight ratios.

The need for long span structures is trendy; hence the use of alternate materials that can enhance these qualities, other than steel, has to be taken into great consideration by researchers. Carbon fibre reinforced polymer cable is a new material that has demonstrated its efficiency in Bridge engineering. The use of CFRP cable is anticipated to improve the suspen dome performance in a different way. Firstly, its low weight can reduce sagging and increase stiffness which means that the Ernst modulus is higher than that of steel cable.

The formula for this equivalent modulus was developed by J.H Ernst and it is given as:

$$
\frac{E_{e}}{E}=\frac{1}{1+\frac{(\rho l)^{2}}{12 \sigma^{3}}} E
$$

\footnotetext{
${ }^{*}$ Corresponding author: epher2002@yahoo.com

> This is an open access article under the CC-BY license (https://creativecommons.org/licenses/by/4.0/).

(C) Authors retain all copyrights.
} 
Where $E_{e}$ is the equivalent modulus, $E$ the modulus of elasticity, $l$ the horizontal span of the cable, $\rho$ the density of the cable material and $\sigma$ the applied cable stress.

Secondly it possesses a very high strength which is like three times that of steel cable strength. Finally, the natural frequency mode is expected to be higher than that of steel cable. Structure formed with such material should be capable of withstanding static and dynamic loads to give an acceptable static deformation and vibrations in the desired plane. Tensegrity system subjected to dynamic loading caused by wind, impact or earthquake can be sensitive due to been light weight. CFRP cables are known to be light weight hence the need to present significant vibration levels is required before implementation.

From literature, it is realized that research on tensegrity system [3-7] has been limited to the application of steel cables. Indeed, literature [1] indicates that the application of tensegrity system in a suspen dome has also been limited to steel cables [8-15], including research findings on static, dynamics, stability, fire resistance, pretension and geometrical imperfection of the cable structure. Few findings focus on the dynamic behaviour of the structure. For example, Zhou et al [14] investigated the nonlinear buckling and seismic performance of the structure with ANSYS finite element program and concluded that the value of imperfection has a great influence on the structure's stiffness. The applications of CFRP as a tensegity system in a suspen dome are scarce hence studies focusing on the dynamic behavior of CFRP cables as a tensegrity system are few. However, Olofin and Liu [16] investigated the numerical modal behavior of a suspen dome with CFRP cables to understand the pattern. Tensegrity systems are high coupled structure that often experience large displacement and hence the analysis of the geometrical nonlinearity should be considered. Indeed, due to these structural concerns, the dynamic behavior of the system is an issue. An evaluation is required when using light weight material for light weight structural system in order to avoid excessive dynamic response. Tensegrity systems have low self-weight which may cause the suspen dome to experience unfavourable vibration levels in response to loads.

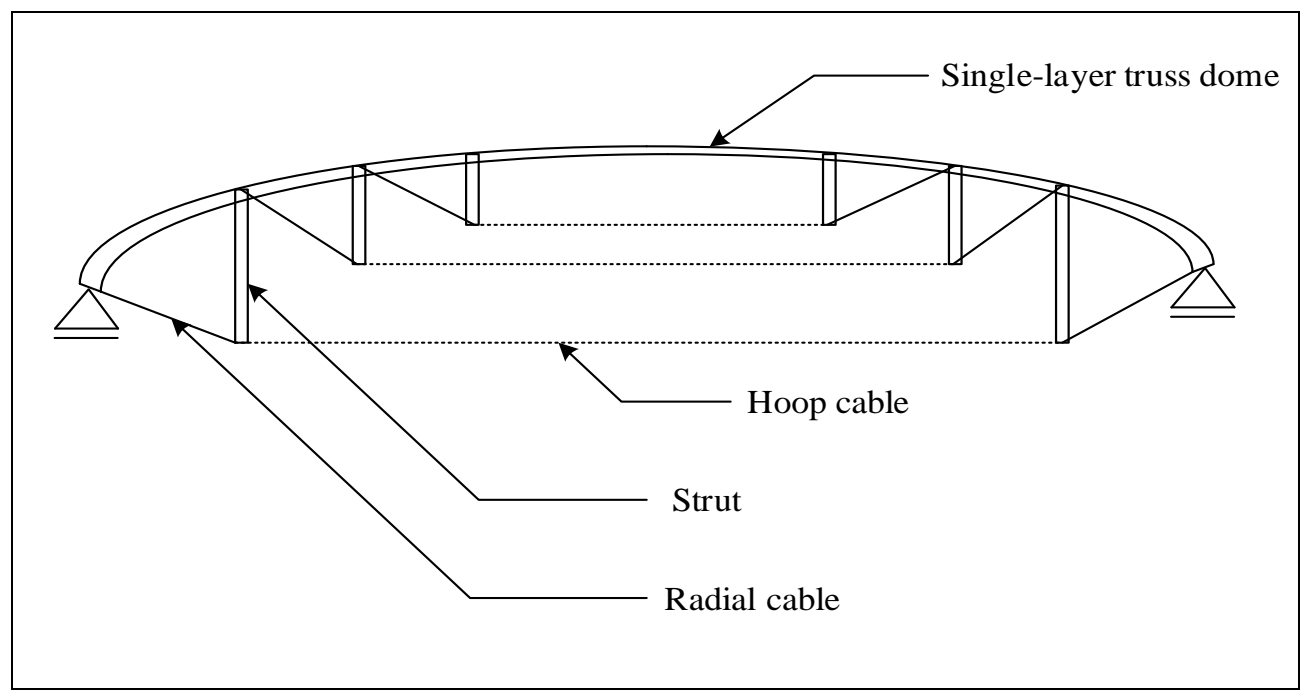

Figure 1. Structural layout of a suspen dome

A realistic design of the suspen dome should be based on weight minimization to ensure that displacement and stresses are within the design codes. Numerical simulations are commonly performed on prototype structures to establish guidelines for designing actual experimental works. Such simulation saves cost and time for experimentation. This paper describes the transient behavior of CFRP cables as a tensegrity structure and comparing its response to the traditional steel cables to determine if CFRP cables can replace the traditional steel material.

\section{Description of the Structure}

The structure used for the numerical simulation has a span of $4 \mathrm{~m}$ and a rise of $0.4 \mathrm{~m}$ (Figure 2) with a point load on $200 \mathrm{~N}$. It is composed of 12 struts, 2 hoop cables and radical cables. The prototype was simulated using ANSYS. 


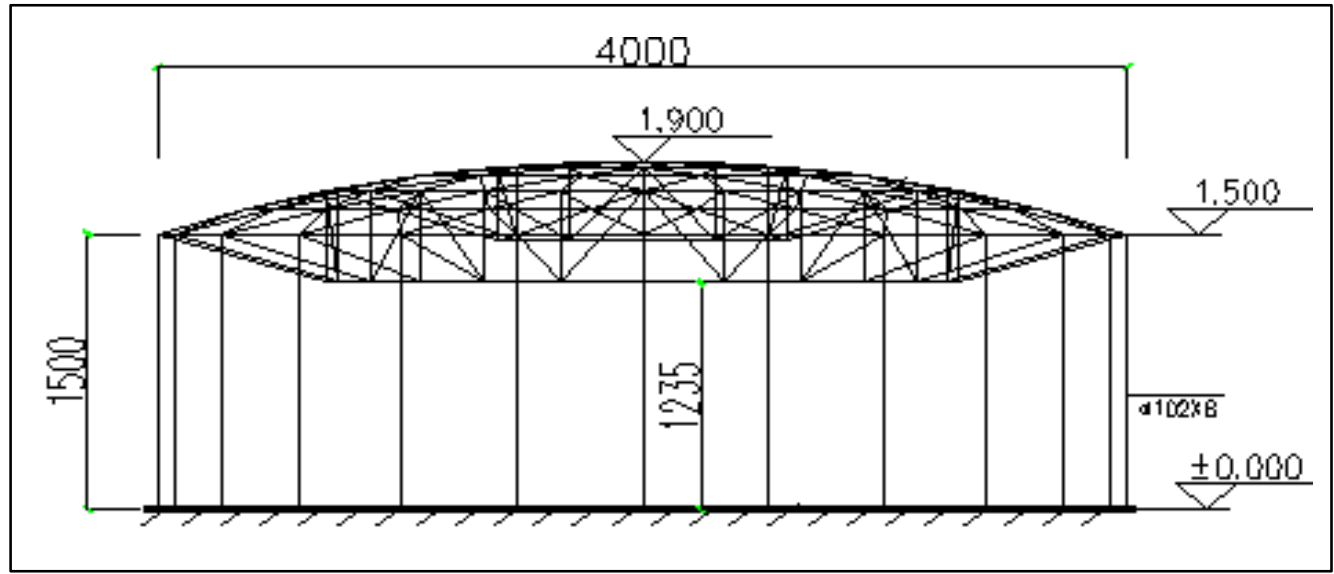

Figure 2. Elevation view

\subsection{Material Properties}

The application of materials in ANSYS modelling is significant; real values of the material properties are inputted into ANSYS as illustrated in Table 1.

Table 1. Material propetires

\begin{tabular}{ccc}
\hline Properties & CFRP cable & Steel cable \\
\hline Modulus of Elasticity $\left(\mathrm{N} / \mathrm{mm}^{2}\right)$ & 160,000 & 180,000 \\
Possion & 0.3 & 0.3 \\
Density $\left(\mathrm{kg} / \mathrm{m}^{3}\right)$ & 1600 & 7850 \\
\hline
\end{tabular}

\subsection{Finite Element Modelling}

A suspen dome structure is made up of series of beams and truss elements. Two types of elements were selected for the analyses of the structure, namely: link 10 and beam188. The model is made up of 1640 elements and 1368 nodes. Link 10 element is a uniaxial 3-D elastic truss element with tension only (or compression only) capability. The element has three degrees of freedom at each node: translation in $\mathrm{x}, \mathrm{y}$ and $\mathrm{z}$ direction of the nodal, translation in node $\mathrm{x}, \mathrm{y}$ and $\mathrm{z}$ direction [17]. Figure 3. illustrates the element.

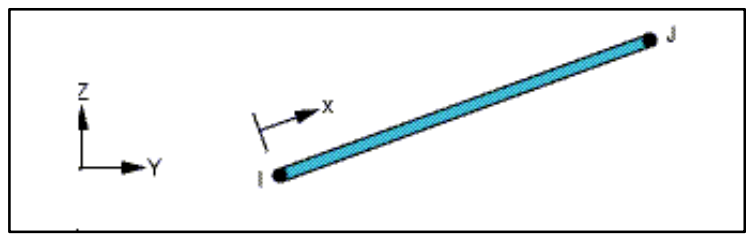

Figure 3. Link 10 geometry [17]

Beam 188 is an element to analyze slender to moderately thick structures. It is a quadratic 3-node beam element in 3-D, having a six to seven degree of freedom at each node [17]. This is illustrated in Figure 4.

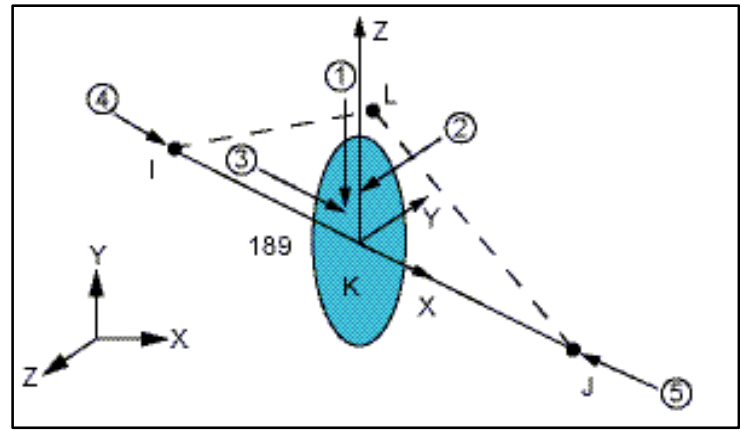

Figure 4. Beam 188 geometry [17]

A full span loading is considered during the simulation as shown in Figure 5, the red dot represents the point loads. The tensegrity members are connected by pin-joint. Pin connected suspen dome system is considered because the rise-to-span ratio is small [8]. The following issues are considered: 
- The external loads are applied at node;

- The self-weight is transferred to nodes as point loads;

- The hoop cable cannot slide towards the cable strut joints;

- Cables are elastic;

- The strut cable is centrally loaded and perfectly straight:

- Loading conditions are modeled using finite element method.

In order to validate the numerical simulation of the system, its simulation application is considered as illustrated in Figure 6.

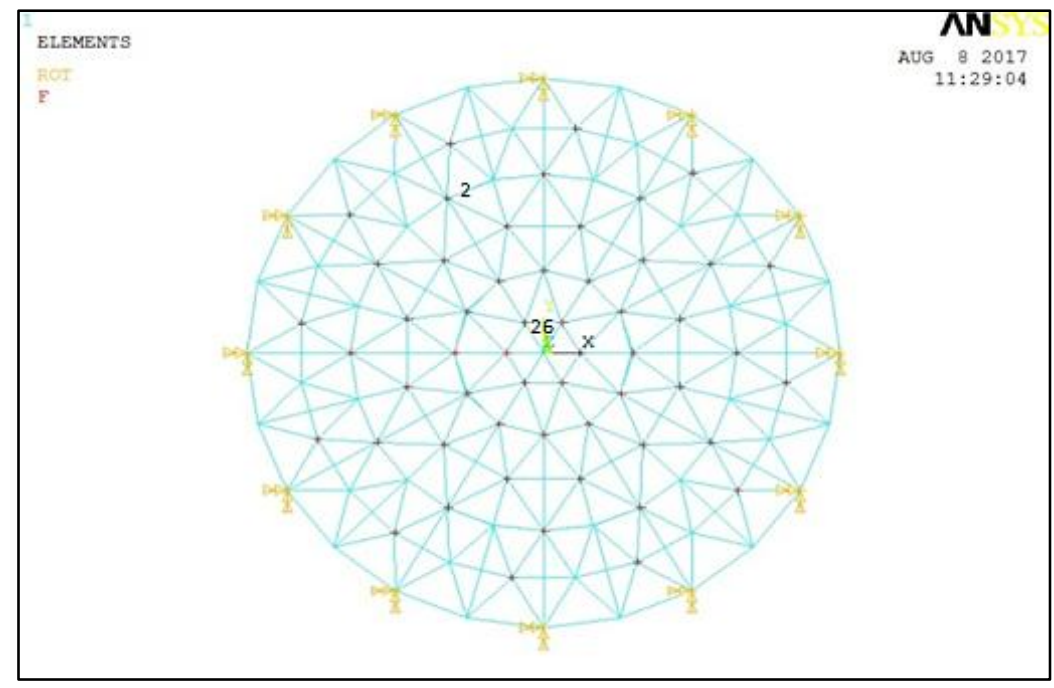

Figure 5. FE model of the suspen dome

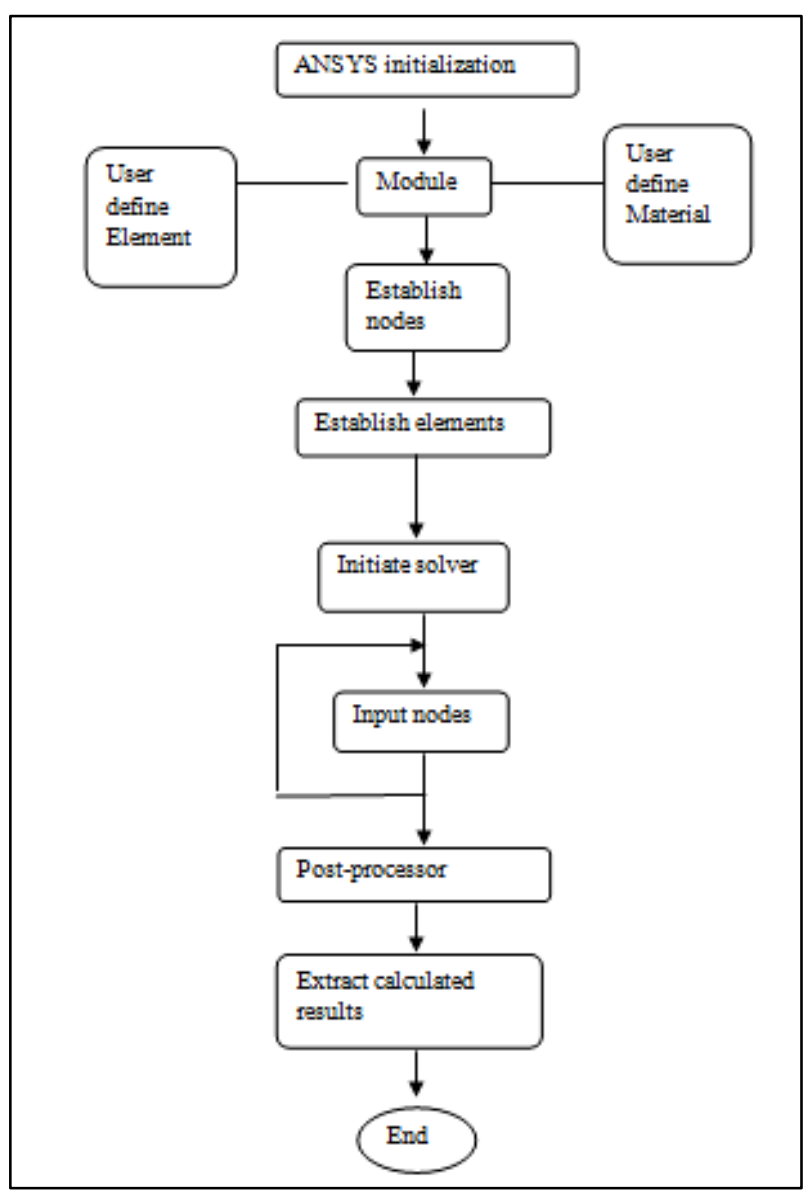

Figure 6. Simulation Algorithm 


\section{Modal Analysis}

The differential equation of motion for a multiple degree of freedom system is given as:

$M \ddot{x}+C \dot{x}+K x=p(t)$

Where $\mathrm{M}, \mathrm{C}$ and $\mathrm{K}$ are matrices describing the mass, damping and stiffness of the structure, $p(t)$ is a vector of external forces and $\mathrm{x}$ is a vector of displacement. Similarly the tangential stiffness matrix is given as:

$$
K_{T}=K_{E}+K_{G}
$$

For the development of finite element model of the structure, the mass and stiffness matrix are given as:

$$
\begin{aligned}
& K_{E}=\left(\frac{E A}{L}\right)\left[\begin{array}{cc}
I_{x} & -I_{x} \\
-I_{x} & I_{x}
\end{array}\right] \\
& K_{G}=\left(\frac{T}{L}\right)\left[\begin{array}{cc}
I_{y} & -I_{y} \\
-I_{y} & I_{y}
\end{array}\right] \\
& M=\left(\frac{m}{6}\right)\left[\begin{array}{cc}
2 I_{y} & -I_{y} \\
-I_{y} & 2 I_{y}
\end{array}\right] \\
& I_{x}=\left[\begin{array}{lll}
1 & 0 & 0 \\
0 & 0 & 0 \\
0 & 0 & 0
\end{array}\right] \\
& I_{y}=\left[\begin{array}{lll}
1 & 0 & 0 \\
0 & 1 & 0 \\
0 & 0 & 1
\end{array}\right]
\end{aligned}
$$

Modal analysis is known as free vibration analysis, used to determine the natural frequencies and mode shape of a structure. Modal analysis of the suspen dome with CFRP and steel tensegrity system was performed to determine the vibration characteristics, natural frequencies and mode shapes. Block 3 Lanczos method was employed to extract eigenvalues (natural frequency) and eigenvectors (mode shape). The modal analysis of the suspen dome is conducted by neglecting the damping matrix and the vector applied forces in Equation 1. which takes form as illustrated in Equation 9.

$$
[K]\left\{\phi_{i}\right\}=\lambda_{i}[M]\left\{\phi_{i}\right\}
$$

Where $[K]=$ Stiffness matrix, $[M]=$ Mass matrix, $\left\{\phi_{i}\right\}=$ the eigenvector and $\lambda_{i}=$ eigenvalues.

The spectral decomposition of matrix $\left[\mathrm{M}^{-1} \mathrm{~K}\right]$ yields the natural frequencies and corresponding mode shape of the suspen-dome. Based on virtual works in dynamics, the Newton Raphson iteration and neglecting effects of damping matrix, the governing dynamic equilibrium equation is:

$$
M^{t+\Delta t} \ddot{U}^{(k+1)}+K^{(k)} \Delta U^{(k+1)}={ }^{t+\Delta t} R-{ }^{t+\Delta t} F^{k}
$$

Where $\mathrm{k}, \mathrm{k}+1$ represents iteration based with time steps. With Newmark approximations

$$
{ }^{t+\Delta t} \ddot{U}=\frac{1}{\beta \Delta t^{2}}\left({ }^{t+\Delta t} U-{ }^{t} U\right)-\frac{1}{\beta \Delta t} \cdot \dot{U}-\frac{1}{2 \beta}{ }^{t} \ddot{U}+{ }^{t} \ddot{U}
$$

Introducing iterations $\mathrm{k}, \mathrm{k}+1$ within the time step

$$
{ }^{t+\Delta t} \ddot{U}^{(k+1)}=\frac{1}{\beta \Delta t^{2}}\left({ }^{t+\Delta t} U^{(k)}-{ }^{t} U+\Delta U^{(k+1)}\right)-\frac{1}{\beta \Delta t} \cdot{ }^{t} \dot{U}-\frac{1}{2 \beta}{ }^{t} \ddot{U}+{ }^{t} \ddot{U}
$$

Hence equation (12) becomes

$$
\left({ }^{t+\Delta t} K^{(k)}+\frac{M}{\beta \Delta t^{2}}\right) \Delta U^{(k+1)}={ }^{t+\Delta t} R-{ }^{t+\Delta t} F^{(k)}-M\left\{\frac{1}{\beta \Delta t^{2}}\left({ }^{t+\Delta t} U^{(k)}-{ }^{t+\Delta t} U\right)-\frac{1}{\beta \Delta t}{ }^{t} U-\left(\frac{1}{2 \beta}-1\right){ }^{t} \ddot{U}\right\}
$$


The results of the modal analysis was carried out, using ANSYS are given in Figure 7. The influence of frame support due to earthquake is ignored. Twenty self-vibrating frequencies are shown in Figure 7, the first and the last of which are illustrated in Figures 8 and 9.

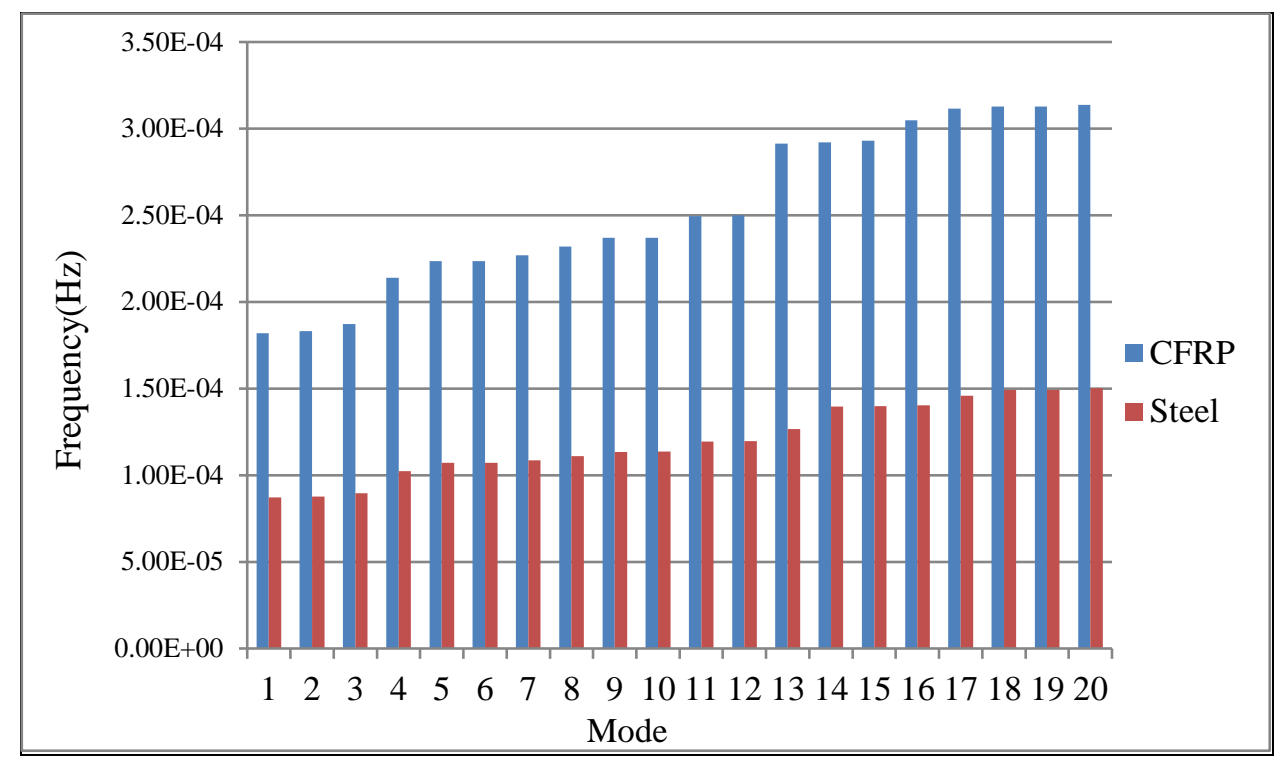

Figure 7. Twenty self-vibrating frequencies of the structure $(\mathrm{Hz})$
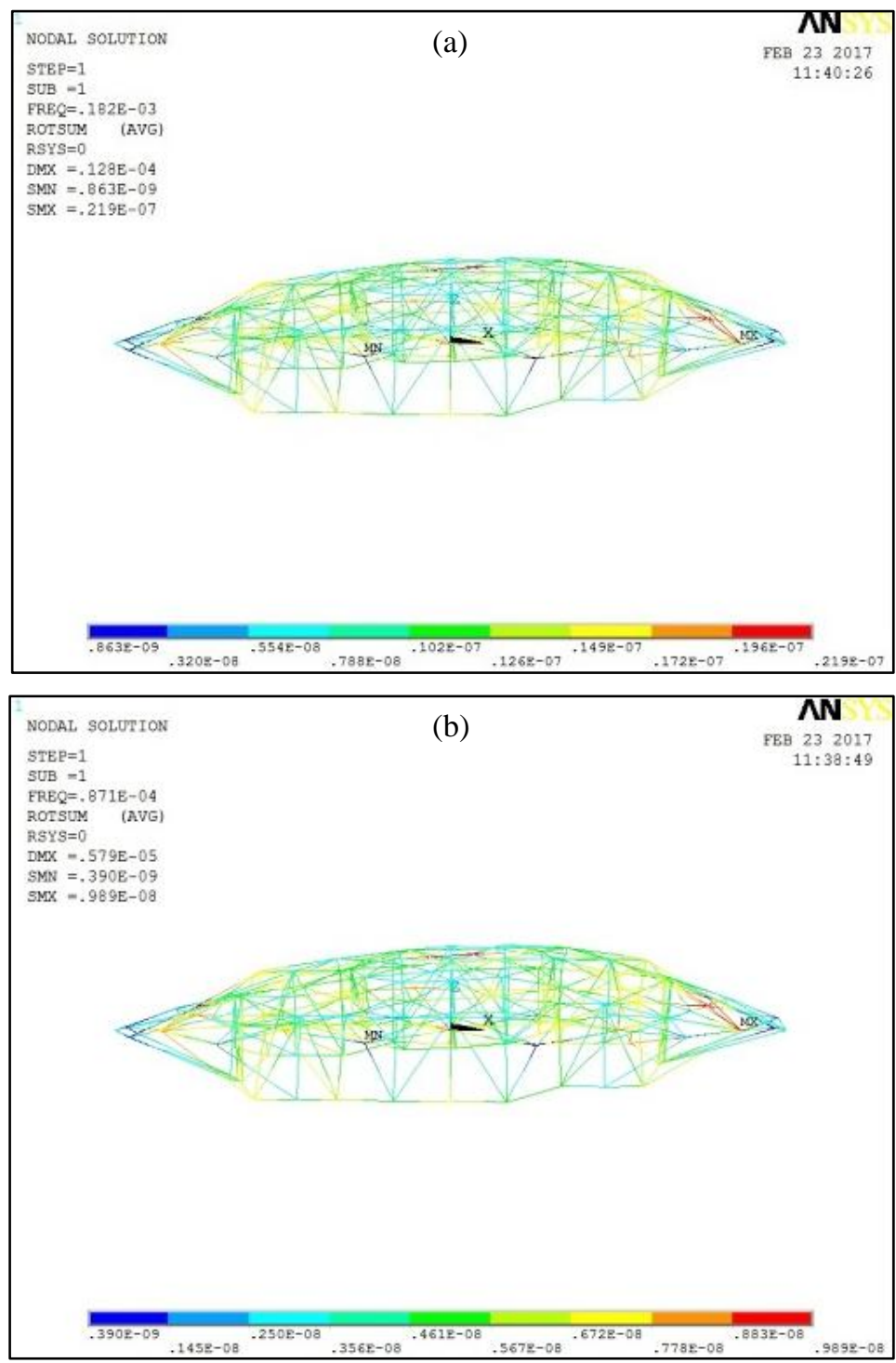

Figure 8. First Vibration Mode (a) CFRP response; (b) Steel response 


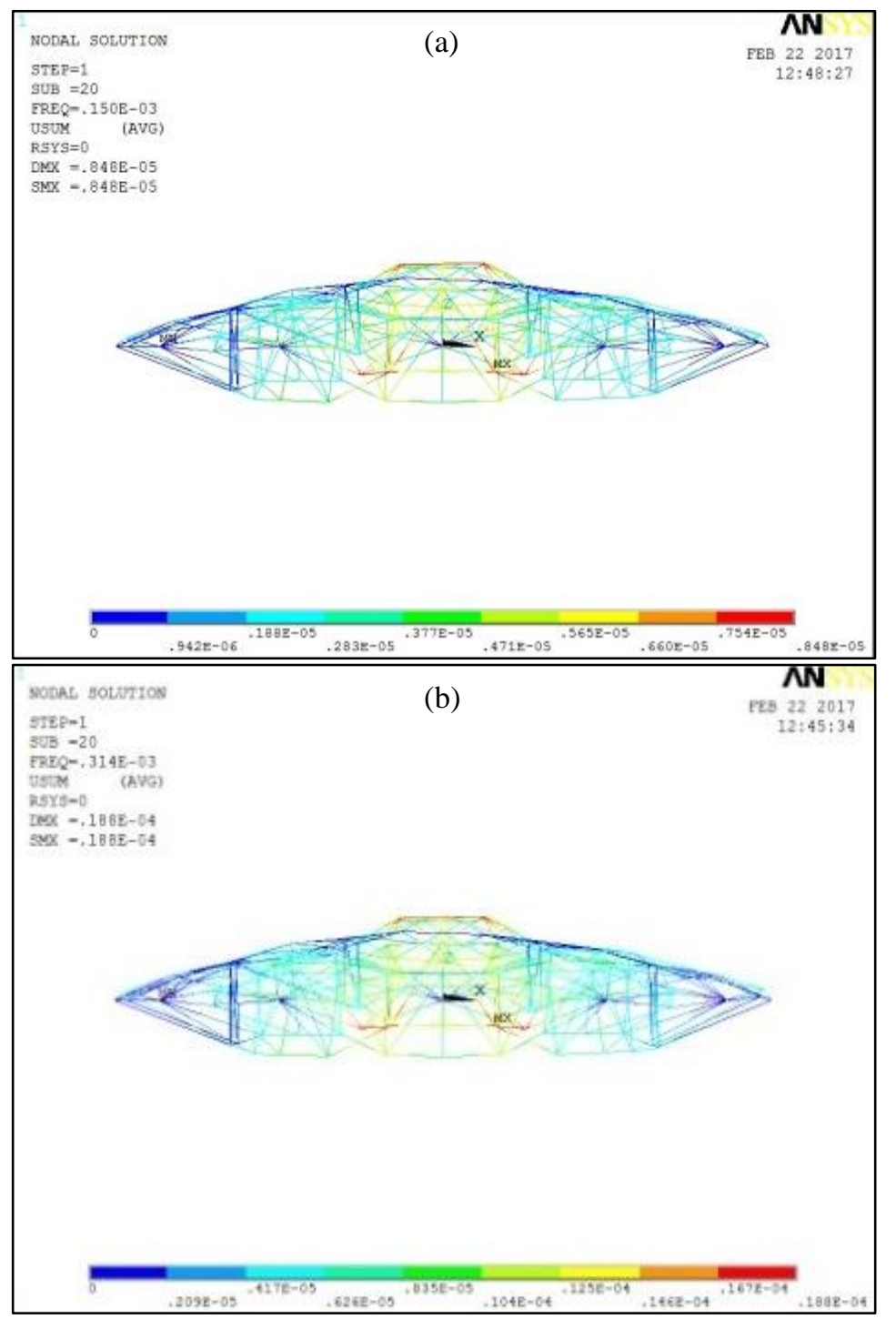

Figure 9. Twentieth Vibration Mode (a) CFRP response; (b) Steel response

The lowest frequency is of great importance because it is associated with wind and wave forces. The fundamental frequency of CFRP tensegrity system from the modal analysis was $0.18190 \mathrm{E}-03 \mathrm{~Hz}$ as shown in Figure 7 . which is sufficiently higher than that of steel with the frequency of $0.87103 \mathrm{E}-04 \mathrm{~Hz}$. Based on the comparison with steel, the modal analysis results show the modes with close frequencies and symmetrical shapes. This explains the configuration of the structure. The mode shapes invole both synchronous and asynchronous vertical deformation.

To further understand the behavior of the structure, the level of stress for the first natural frequencies is plotted. From the studied solution, CFRP cables stress level is similar to that of steel. The results illustrated in Figure 10. can be considered in the dynamic behavior as additional parameter in the design process of the suspen dome. The values obtained can be used to identify design solutions.

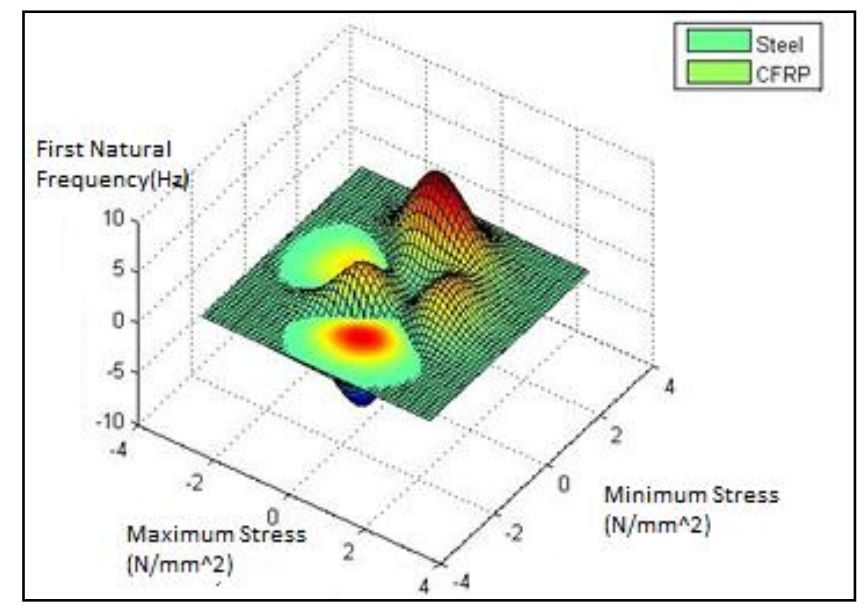

Figure 10. Variation of first natural frequency with respect to the maximum and minimum stress generated in the cables 
In addition and based on the displacement value, CFRP cables obtained a value of $0.128 \times 10^{-4} \mathrm{~mm}$ compared to steel with a value of $0.579 \times 10^{-5} \mathrm{~mm}$, the slight difference is due to the light weight of CFRP cables.

\section{Transient Analysis}

The transient analysis gives detailed response of the dynamic behavior of a structure [3]. The transient analysis is preferred for detailed investigation of dynamic response of the suspen dome because of the transient load excitation the structure resonates in its first damped natural frequency. The function of the applied force can be expressed as:

$$
f(t)=f_{\max } e^{i(\Omega+\Psi)}
$$

Where:

$$
\begin{aligned}
& f_{\max }: \text { Amplitude of the force } \\
& \Omega: \text { Imposed circular frequency } \\
& \Psi: \text { Force phase shift }
\end{aligned}
$$

In the transient analysis, each force vector represents a load impulse of $200 \mathrm{~N}$ acting during the time interval of $0 \mathrm{~s}<\mathrm{t}<0.001 \mathrm{~s}$. The range of time of interest is considered to be $0 s<t<0.1 s$ and $0 s<t<2 s$. Hence, 1000 steps are performed. The size of the time step is governed by the maximum frequency of the structure. The smaller the time step, the higher the mode frequency.

The response of the structure under time and varying load considered in the case study is illustrated in Figure 11. which shows the transient response of the structure measured at a typical node in the global z-direction. It can be observed that for steel tensegrity system, it takes a cycle of 20 seconds to change from its equilibrium state; whereas for carbon fibre reinforced polymer, it takes 3 cycles of 20 seconds to change from its steady state. Because of the transient load excitation, the structure resonates in its first damped natural frequency. The displacements time history for both CFRP and steel at z-direction are illustrated in Figure 11. Similarly, Figure 12. shows the transient response at y-direction with approximately 3 cycles in one second for steel tensegrity system and 6 cycles in one second for carbon fibre reinforced polymer.
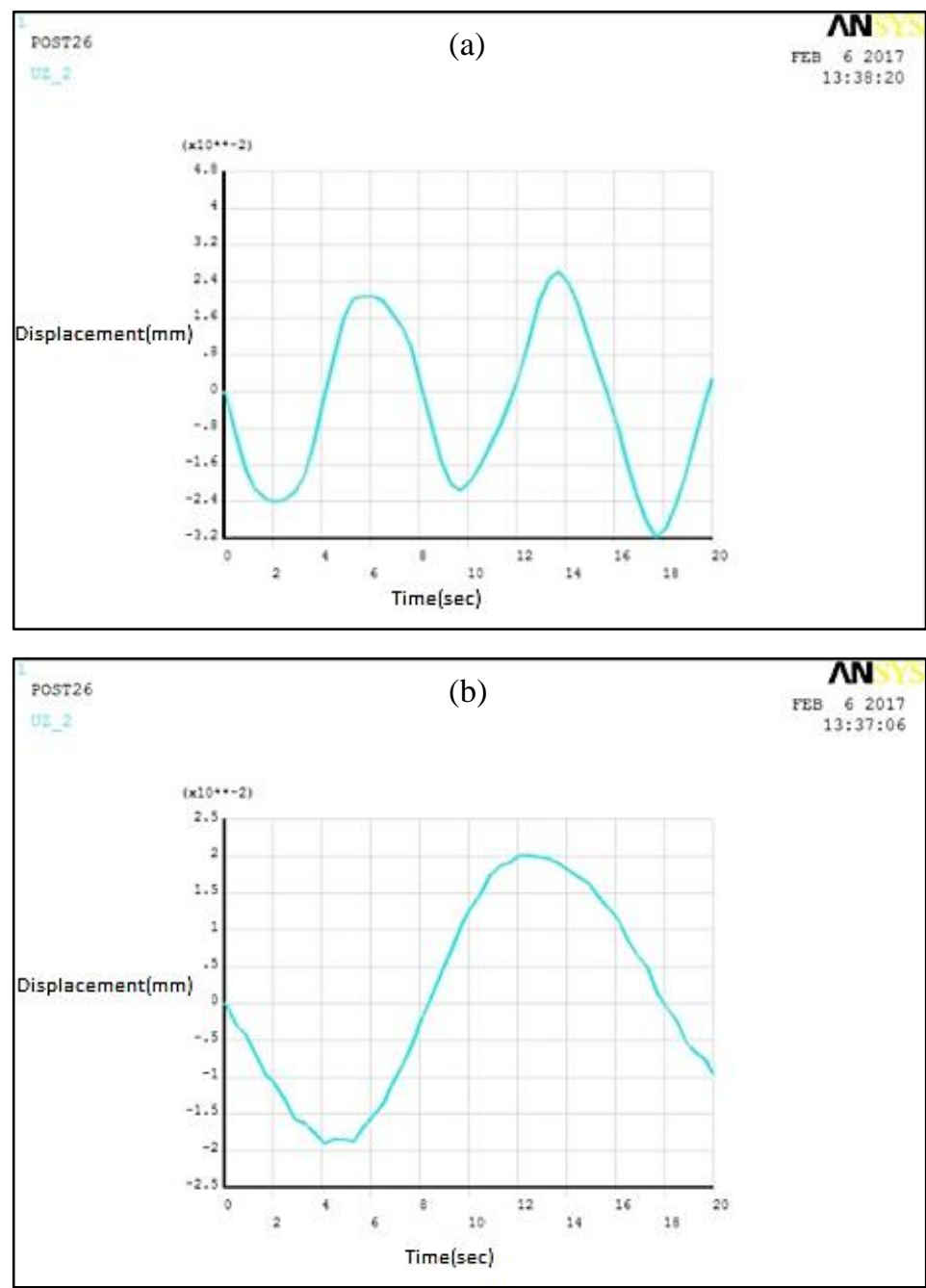

Figure 11. Amplitude spectra of displacement of node 26 (200 N at node 2) Z-axis (a) CFRP response; (b) Steel response 

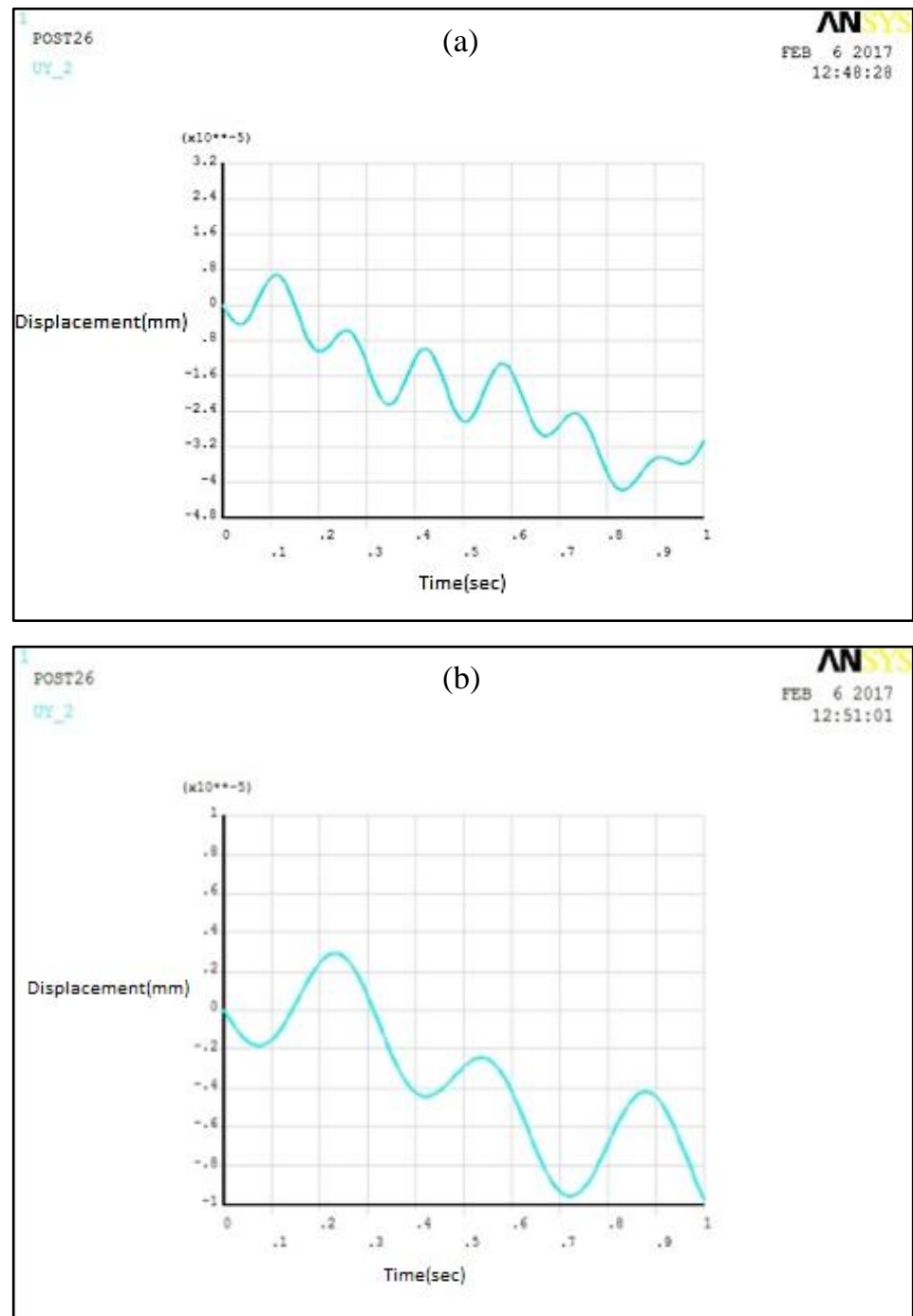

Figure 12. Amplitude spectra of displacement of node 26 (200 $\mathrm{N}$ at node 2) Y-axis (a) CFRP response; (b) Steel

The responses of the structure are of utmost interest in transient dynamic analysis. The maximum displacement of 0.02mm@12.9 sec was obtained for steel and one of $0.026 \mathrm{~mm} @ 13.1 \mathrm{sec}$ for CFRP from the transient analysis. Thus, the carbon fibre reinforced polymer displacement values display good agreements with those of steel. The vibration modes are very complicated. Low order vibrations are vertical. Similarly, value attributes for other members of the structure were obtained.

\section{Conclusion}

The application of finite element simulation method for structure analysis gives a preliminary assessment of the behavioral performance of a structure before actual experimental construction. Applied in this study for the analysis of steel and CFRP cables, the vibration of the CFRP cable is higher than that of steel due to its high stiffness-to-weight ratio and less curvature under gravity loads. This is so because tensegrity systems are lightweight and have relative low structural damping. In this study, the results of the eigen frequency analysis showed that CFRP tensegrity system can withstand dynamic loads. The results also showed that the natural frequencies of CFRP cables are influenced by the self-weight value being lower than that of steel, hence, it is possible to consider the dynamic behavior as a parameter in the design process of the tensegrity system.

It can be concluded that the study showed that CFRP tensegrity system could compete favourably with the traditional steel tensegrity system. Based on the topology of the design it satisfies the design requirements. This justifies the study of CFRP cables as a tensegrity system in a suspen dome which is aimed to be a novel contribution towards identifying its potential application.

In view of the uncertain accuracy with various numerical and approximate analytical methods, experimental methods are required to verify these theoretical results. However, the results indicate that, from a technical point of view, CFRP cables can perform better than steel cables as tensegrity system for a suspen dome 


\section{References}

[1] Olofin, IfeOlorun, and Ronggui Liu. "Suspen-Dome System: A Fascinating Space Structure." The Open Civil Engineering Journal 11, no. 1 (2017).

[2] Subramanian, N. Space Structures: Principles And Practice, Multi-Science Publishing Co Ltd, 2006.

[3] Bel Hadj Ali N, Smith I F C"Dynamic behavior and vibration control of a tensegrity structure", International Journal of Solids and Structures, 47(9) (2010): 1285-1296.

[4] Shirko Faroughi, Hamed Haddad Khodaparast, Michael I. Friswell "Non-linear dynamic analysis of tensegrity structures using a co-rotational method", International Journal of Non-Linear Mechanics, 6 ,(2015): 55-65.

[5] Kebiche, K, Kazi-Aoual M N, Motro R, "Geometrical non-linear analysis of tensegrity systems", Engineering Structures, 21(9) (1999): 864-876.

[6] Josep M. Mirats Tur, Sergi Hernàndez Juan, "Tensegrity frameworks Dynamic analysis review and open problems", Mechanism and Machine Theory, 44(1) (2009): 1-18.

[7] Motro R,Najari P. Jouanna P, "Static and Dynamic Analysis of Tensegrity Systems", Shell and Spatial Structures: Computational Aspects(1987): 270-279.

[8] Kitipornchai S, Kang W, Fai Lam H and Albermani F, "Factor affecting the design and construction of Lamella suspen-dome system", Journal of Construction Steel Research, 61 (2005): 764-785.

[9] Guo J.M, Dong S.L and Yuan X.F, "Research on static property of suspen-dome structure under heap load", Advanced Steel Construction, 8, (2012): 37-152.

[10] Kang W, .Chen Z, Lam H and Zuo C, "Analysis and design of the general and outmost ring stiffened suspen-dome structure", Engineering structures,25,(2003): 1685-1695.

[11] Zhang Z, Cao Q, Dong S.L and Fu X, "Structural design of a practical suspen-dome", Advanced Steel Construction, vol.4, (2008): 323-340.

[12] Kawaguchi M, Abe M, Hatabo T, Latemichi I, Fujiwara S, Matsufuji H, Yoshida H and Ama Y, "Structural tests on the system dome system", Proceeding of IASS-ASCE International Symposium, (1994): 383-392.

[13] Chen Z, Renzhang Y, Xiaodun W, Hongbo L and Xiao X, "Experimental researches on suspen-dome structure with rolling cable-strut joint", Advanced steel construction,11, (2015): 15-38.

[14] Zhou Z, Yu-Long F, Shao-Ping M and Wu, J, "A novel form analysis method considering pretension process for suspen-dome structures", KSCE Journal of Civil Engineering, 18, (2014): 1411-1420.

[15] Shekastehband B., Abedi K., Dianat N., "Experimental and numerical studies on the progressive collapse behavior of tensegrity systems", International journal of space structures,29(1), (2014).

[16] Olofin I and LiuR,"Numerical modal analysis of a suspen-dome with carbon fibre reinforced polymer tensegrity system", Modelling, Measurement and Control Series A, 89,(2015): 13-24.

[17] ANSYS, Structural Analysis Guide, ANSYS. Inc, (2008). 